\title{
- Probióticos e prebióticos: realidade na avicultura industrial moderna
}

\section{Probiotics and prebiotics: the reality in the modern poultry industry}

*Laboratório de Ornitopatologia
Departamento de Clínica Veterinária
FMVZ- UNESP- Distrito de Rubião Júnior
CEP:: 18618-000 - Botucatu - SP
Fone: (0XX14) 820-6293.
Fax: (0XX14) 820-6067.
e-mail: andreatti@laser.com.br

* Raphael Lúcio Andreatti Filho ${ }^{1}$-CRMV-SPn ${ }^{0} 4189$. Homero Marcos Sampaio ${ }^{2}$-CRMV-ESn 0370 .

1 Professor Assistente Doutor da Disciplina de Ornitopatologia - FMVZ - UNESP - Botucatu - SP.

2 Médico Veterinário - Mestrando em Medicina Veterinária - FMVZ - UNESP - Botucatu - SP.

\section{RESUMO}

Nesse artigo, revisam-se os usos de probióticos e prebióticos na avicultura industrial. A importância dos alimentos funcionais que ganham espaço dia a dia, é abordada através da composição e atividade da microbiota intestinal normal das aves, do mecanismo de ação dos probióticos e prebióticos e dos seus benefícios à avicultura. Alimentos funcionais tendem a substituir paulatinamente os já tradicionais promotores de crescimento, reduzindo-se os custos de produção e proporcionando ao consumidor produtos avícolas de melhor qualidade.

Unitermos: probióticos, prebióticos, simbióticos, alimentos funcionais, exclusão competitiva, avicultura.

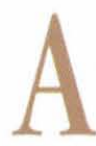

constante evolução técnica pela qual passa a avicultura industrial mundial tem possibilitado a obtenção de produtos avícolas de baixo custo, saudáveis e altamente nutritivos, redundando no evidente favorecimento ao consumidor final. Consumidor esse que pode ser ainda mais beneficiado, mediante a redução do uso de antibióticos pela indústria avícola, paulatinamente substituídos pelos probióticos e prebióticos. Produtos denominados probióticos e prebióticos, embora não apresentem todas as ações benéficas dos antibióticos, não determinam resíduos nos produtos de origem animal e não desenvolvem resistência às drogas utilizadas em se- res humanos, por serem produtos essencialmente naturais, o que já os coloca em simpática posição em todos os segmentos da cadeia de produção e consumo de proteína animal. Se, além dessas características, pudermos contar com a redução na colonização de patógenos potencialmente perigosos à saúde avícola e humana, como, por exemplo, bactérias do gênero Salmonella, além de propiciar melhores índices zooeconômicos, estaremos diante de idéias, conceitos e produtos que modificarão os métodos de criação e produção avícolas. Portanto, é exatamente o uso de probióticos e prebióticos na avicultura industrial que abordaremos nesse artigo. 


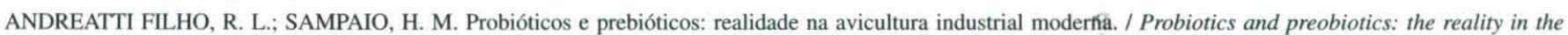
modern poultry industry / Rev. educ. contin. CRMV-SP / Continuous Education Journal CRMV-SP, São Paulo, volume 2, fascículo 3, p. 059 - 071, 1999.

$\mathrm{O}$ efeito protetor da microbiota industrial contra a colonização por patógenos é conhecido há muitos anos e tem sido amplamente aceito. METCHNIKOFF (1907) foi o primeiro a observar que agricultores búlgaros consumindo leite fermentado, contendo Lactobacillus acidophilus, apresentavam maior longevidade, o que levou à suposição de RETTGER e CHAPLIN (1921) de que esse efeito benéfico era proveniente da colonização intestinal pelo L. acidophilus. Em aves, os trabalhos de NURMI e RANTALA (1973), demonstrando que a microbiota de aves adultas normais apresentava efeito protetor em pintos contra a infecção por Salmonella spp., e de TORTUERO (1973), indicando melhoria nos índices zooeconômicos, como melhor conversão alimentar e aumento no ganho de peso em aves que receberam $L$. acidophilus, abriram caminho para uma série de investigações sobre o tema. Em condições normais, as aves jovens recebem a microbiota principalmente das mães, e, em galinhas e perus, a transferência de microrganismos é muito eficiente quando os recém-nascidos são criados próximos aos adultos. Infelizmente, os sistemas modernos de produção em massa, atualmente desenvolvidos pela indústria avícola, impossibilitam esse contato, com o conseqüente retardo no desenvolvimento da microbiota intestinal protetora.

A microbiota intestinal é composta de inúmeras espécies bacterianas, formando um sistema complexo e dinâmico, responsável por influenciar decisivamente fatores microbiológicos, imunológicos, fisiológicos e bioquímicos no hospedeiro (TANNOCK, 1998). A administração de microrganismos da microbiota intestinal de aves pode determinar alguma proteção às aves contra a colonização por alguns patógenos, como Salmonella spp. (ANDREATTI FILHO et al.1997, 1998; CORRIER et al.1995; NURMI e RANTALA, 1973; SCHNEITZ., 1992; STAVRIC, 1992; ZIPRIN et al. 1993), Escherichia coli (JIN et al. 1996) e Campylobacter spp. (BAILEY, 1993). Já em agentes que são hospedeiros específicos, como $S$. gallinarum que causa infecção sistêmica e não coloniza primariamente os cecos, a microbiota intestinal não tem sucesso no seu controle (SILVA et al. 1981).

DAY (1992) define o termo exclusão competitiva (EC) como a inabilidade de uma população de microrganismos em estabelecer-se no intestino, em razão da presença de outra população bacteriana. Em outras palavras, ou uma população de microrganismos apresenta maior sucesso ao estabelecer-se em um determinado ambiente, ou ela é produtora de algum metabólito que seja tóxico para outra população de microrganismos. Esta habilidade de proteção pela microbiota intestinal, hoje conhecida como EC, foi primeiramente descrita pelo professor Esko Nurmi na Finlândia, em 1973 (NURMI e RANTALA, 1973). Em seus experimentos, ele observou que o conteúdo intestinal de aves adultas normais, administrado oralmente às aves com um dia de idade, altera sua sensibilidade à infecção por Salmonella spp., prevenindo o estabelecimento desta no intestino. Essa idéia tornou-se conhecida como o "conceito de Nurmi". A obstrução desenvolvida contra a microbiota intestinal normal, que ocorre na moderna produção avícola, conduz a severos surtos de infecção por Salmonella spp., devido a falha na defesa contra essas bactérias patogênicas.

\section{Microbiota intestinal: atividade e composição}

A colonização da mucosa intestinal por grande e diversificado número de bactérias é achado normal no homem e nos animais, incluindo as aves. Geralmente os primeiros gêneros e espécies bacterianas que colonizam o trato intestinal persistem ao longo da vida do hospedeiro, passando a compor a microbiota intestinal. No hospedeiro, essas bactérias devem encontrar as condições propícias para a colonização e persistência, como temperatura e $\mathrm{pH}$ adequados, e oferta de nutrientes, entre outras (MILES, 1993).

Entre os principais gêneros bacterianos que são identificados na microbiota cecal de aves, observam-se invariavelmente a presença da Bacillus, Bacteroides, Bifidobacterium, Citrobacter, Clostridium, Enterobacter, Enterococcus, Escherichia, Eubacterium, Fusobacterium, Lactobacillus, Lactococcus, Pediococcus, Peptostreptococcus, Propionibacterium, Ruminococcus, Serratia, Veillonella e Streptococcus, entre outros (IMPEY et al. 1982; OYARZABAL e CONNER, 1995; SALANITRO et al. 1978). As bactérias que habitam o trato intestinal podem estabelecer-se de duas formas: em íntima associação com o epitélio intestinal ou livre na luz intestinal, mas multiplicando-se mais rapidamente do que sua eliminação pelo peristaltismo intestinal. Esses são os mecanismos que ocorrem, por exemplo, com algumas espécies de Lactobacillus e Enterococcus, respectivamente (MILES, 1993). Outras espécies bacterianas não apresentam capacidade de aderir ao epitélio intestinal, tampouco multiplicam-se em tempo que compense a eliminação pelo peristaltismo, mas permanecem no intestino agregando-se a outras bactérias que por sua vez, estão aderidas à mucosa entérica (GUSILS et al. 1999).

Qualquer fator que leve ao desequilíbrio da microbiota intestinal, como o uso indevido de antimicrobianos e 


\section{REDUZ OS NÍVEIS DE COLESTEROL NO SANGUE}

\section{REDUZ OS NÍVEIS DE AMÔNIA NO SANGUE

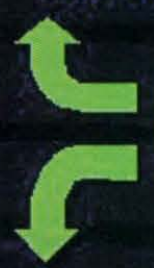 \\ INIBE O CRESCIMENTO DE \\ PATÓgENOS PELA PRODUÇÃO DE ACETATO E LACTATO}

\section{BIFIDOBACTERIUM}

PRODUCÁTO DE VITAMINAS

DO COMPLEXO B E ÁCIDO

FÓLICO

\section{RESTAURA A MICROBIOTA INTESTINAL NORMAL DURANTE TERAPIA COM ANTIBIÓTICOS}

Figura 1 - Propriedades do Bifidobacterium relacionadas com efeito benéfico à saúde humana. Adaptado de GIBSON e ROBERFROID (1995).

estresse de qualquer natureza do hospedeiro, poderá permitir a instalação e a multiplicação de microrganismos patogênicos. Logo, fica evidente que o equilíbrio da microbiota intestinal reflete diretamente em um bom estado de saúde do hospedeiro (MILES, 1993). O trato digestivo das aves é habitado por uma microbiota que tem sua formação iniciada imediatamente após o nascimento das aves, constituindo importante barreira contra a colonização de microrganismos potencialmente patogênicos como Salmonella spp. A susceptibilidade das aves à colonização intestinal por Salmonella spp. é maior durante os primeiros dias de vida, sendo, posteriormente, reduzida à medida que há o desenvolvimento da microbiota intestinal normal. Esta microbiota intestinal aumenta consideravelmente durante as primeiras semanas de vida, até se tornar uma população predominantemente de bactérias anaeróbias (SALANITRO et al. 1978).

Utilizando o esquema de composição bacteriana fecal humano, podemos dividir os inúmeros gêneros que a compõem em benéficos e prejudiciais (Figura 1). Os efeitos patogênicos incluem diarréia, infecções, danos hepáticos, carcinogênese e putrefação intestinal, enquanto os efeitos benéficos à saúde do hospedeiro são determinados pela inibição do crescimento de bactérias patogênicas, estímulo às funções do sistema imune, redução na distensão por gases, melhor digestão e absor- ção de nutrientes essenciais e síntese de vitaminas (GIBSON e ROBERFROID, 1995). Na composição de um probiótico, dois gêneros, Lactobacillus e Bifidobacterium, são necessariamente comuns, quer em produtos humanos, quer em produtos animais, pois ambos exercem ação estritamente benéfica ao hospedeiro. Espécies de Lactobacillus, até por razões históricas no desenvolvimento dos produtos lácteos, têm lugar garantido nos probióticos. Supondo-se que as outras propriedades não "tradicionalmente conhecidas" sejam advindas do gênero Bifidobacterium: além de suas propriedades já tradicionalmente conhecidas, como o estímulo do sistema imune - por ativação dos macrófagos - e o auxílio na digestão e absorção de nutrientes - em face de seu envolvimento na bioquímica intestinal, especialmente em relação a ação sobre os sais biliares e, também, pela ação inibitória ao crescimento de bactérias patogênicas, em virtude de produção de bacteriocinas, substâncias formadas por peptídeos, proteínas ou complexos protéicos e de carboidratos que agem inibindo o crescimento de outras bactérias (TANNOCK, 1998) têm-se outras, creditadas a algumas espécies de Bifidobacterium, gênero bacteriano que, mais recentemente, adquiriu enorme importância e evidência quanto a presença em probióticos, decorrente da observação da participação em inúmeras funções benéficas ao hospe- 
ANDREATTI FILHO, R. L.; SAMPAIO, H. M. Probióticos e prebióticos: realidade na avicultura industrial moderna. / Probiotics and preobiotics: the reality in the modern poultry industry / Rev. educ. contin. CRMV-SP / Continuous Education Journal CRMV-SP, São Paulo, volume 2, fascículo 3, p. 059 - 071 , 1999.

deiro (Figura 2) (GIBSON e ROBERFROID, 1995), entre as quais a produção de lactato e acetato, que reduzem o $\mathrm{pH}$ do meio, exercendo efeito antibacteriano (RASIC, 1983), excreção de metabólitos que inibem bactérias gram-negativas e positivas patogênicas (GIBSON e ROBERFROID, 1995) produção de vitaminas do grupo B (NISHIZAWA, 1960), ativação do sistema imune contra células malignas (SEKINE et al. 1985) e restauração da microbiota após antibioticoterapia (KORSHUNOV et al. 1985), entre outras.

\section{probióticos: o que são?}

LILLY e STILLWELL (1965) foram os primeiros a utilizar o termo probiótico, observando a ação de microrganismos como promotores de crescimento. Seguiram-se inúmeros trabalhos sobre produtos e processos com o propósito de oferecer proteção contra a infecção por patógenos intestinais e melhor desempenho zootécnico. A maioria desses produtos, compostos por culturas de microrganismos vivos, têm a capacidade de se instalar e proliferar no trato intestinal do hospedeiro. Surgiram várias definições para os probióticos. Geralmente observamos a complementação das definições antecessoras, com a adequação a alguma característi- ca peculiar. FULLER (1989) definiu probiótico como suplemento alimentar composto de microrganismos vivos que beneficiam a saúde do hospedeiro, por meio do equilíbrio da microbiota intestinal. HAVENAAR et al. (1992), complementando a definição proposta por FULLER (1989), definiram probiótico como cultura pura ou composta de microrganismos vivos que, fornecidos ao homem ou aos animais, beneficiam o hospedeiro pelo estímulo das propriedades existentes na microbiota natural. Essas definições são atualmente as mais aceitas e utilizadas no meio científico. Podemos verificar que não há espaço para antibióticos, derivados ou mesmo promotores de crescimento tradicionais no contexto dessas definições.

\section{Probióticos: como funcionam?}

O mecanismo ou mecanismos de como agem os probióticos não estão inteiramente elucidados. Especulase que um ou mais processos, associados ou não, alterariam a atividade e a composição bacteriana intestinal. $\mathrm{O}$ equilíbrio entre os diferentes componentes da microbiota intestinal parece ser fundamental para o funcionamento normal e saudável da função digestiva e geral do hospedeiro. A alta incidência e o constante estresse a que es-

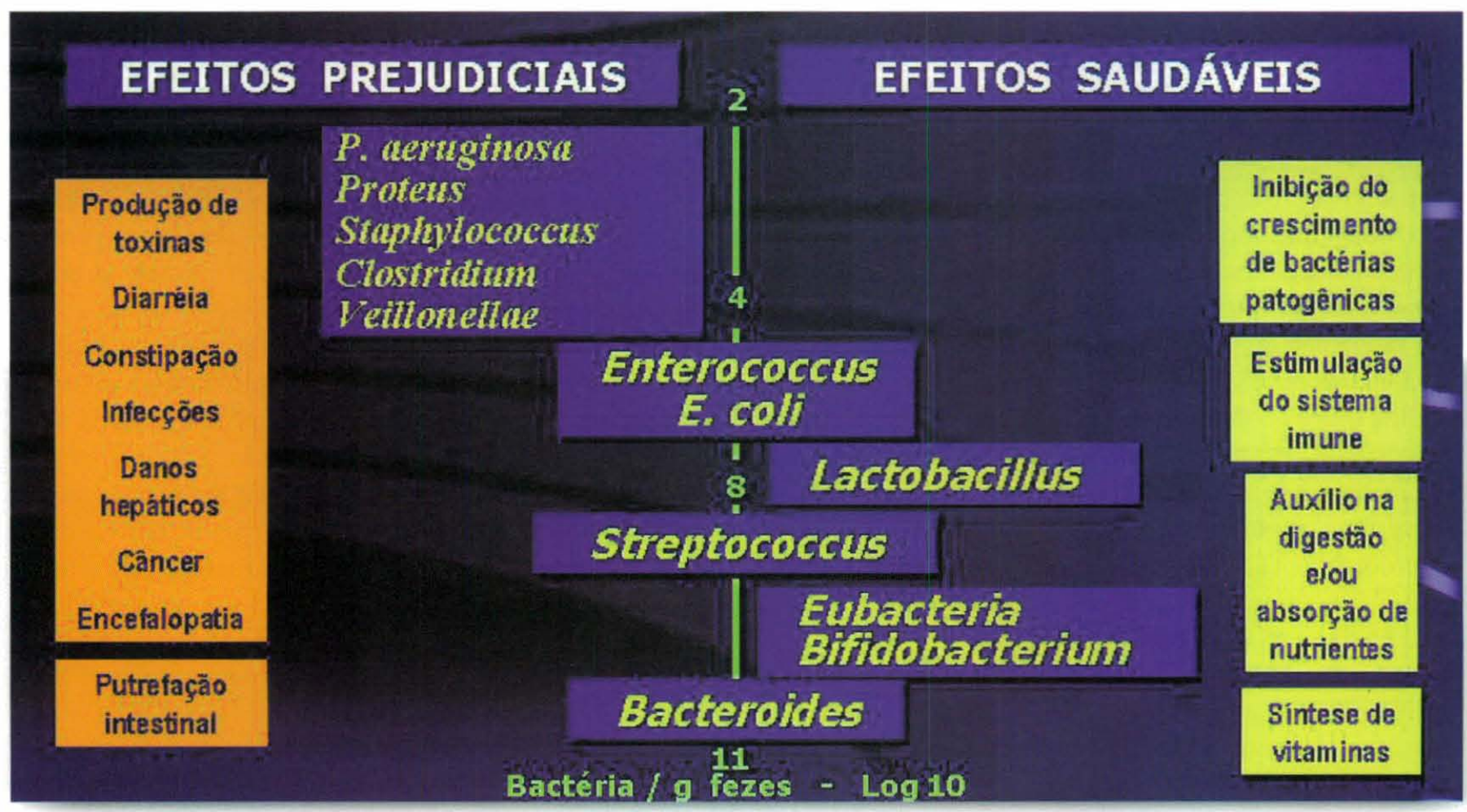

Figura 2 - Esquema da composição da microbiota intestinal humana. Os diferentes gêneros bacterianos estão divididos conforme os efeitos prejudiciais ou benéficos ao hospedeiro. A linha vertical indica o número aproximado de cada um dos gêneros bacterianos nas fezes. Adaptado de GIBSON e ROBERFROID (1995) e FULLER e GIBSON (1997). 


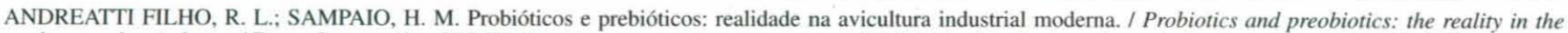
modern poultry industry / Rev. educ. contin. CRMV-SP / Continuous Education Journal CRMV-SP, São Paulo, volume 2, fascículo 3, p. 059 - 071, 1999.

tão expostas as aves em condições normais de criação, invariavelmente, podem alterar o equilíbrio intestinal e predispor as aves a diversas infecções, além de reduzir os índices de produtividade.

Competição por sítios de ligação. Após quase trinta anos do trabalho pioneiro de NURMI e RANTALA (1973), inúmeras foram as pesquisas realizadas para verificar a eficácia da EC no controle de bactérias patogênicas, especialmente Salmonella spp. O bloqueio dos sítios de ligação (receptores) na mucosa entérica pelas bactérias intestinais pode reduzir a área de interação nos cecos pelas bactérias patogênicas. BAILEY (1993) e JIN et al. (1996) concluíram que a ocupação física dos sítios intestinais pela microbiota normal, especialmente Lactobacillus spp., poderia ser mais importante que outros fatores propostos para EC. Desse mesmo modo, outros trabalhos, como os de CONWAY et al. (1987) e STAVRIC (1987), confirmaram que a colonização intestinal por grande quantidade de bactérias pertencentes à microbiota intestinal normal, especialmente Lactobacillus spp. e Bifidobacterium spp., formando uma barreira física às bactérias patogênicas pelo preenchimento dos sítios de ligação, respaldaria a teoria de que esse mecanismo possa ser fator primário à EC (JIN et al. 1997; FULLER e GIBSON, 1997).

Substâncias antibacterianas. Bactérias da microbiota intestinal e/ou componentes dos probióticos podem produzir e liberar compostos como as bacteriocinas, ácidos orgânicos e peróxido de hidrogênio, que teriam ação antibacteriana especialmente em relação às bactérias patogênicas. As bacteriocinas, definidas por TAGG et al. (1976) como substâncias produzidas por bactérias que apresentam ação bactericida ou antagônica a outros tipos de bactérias, são freqüentemente relacionadas com a ação dos probióticos. Bacteriocinas produzidas por diversas espécies de Lactobacillus, como a lactocina F (KLAENHAMMER et al. 1994), lactocina 27 (UPRETI e HINDSDILL, 1975) e a lactocidina (VICENT et al. 1959), são as mais estudadas. Apresentam atividade inibitória tanto para bactérias gramnegativas quanto para gram-positivas, como Salmonella spp., Escherichia coli e Staphylococcus spp., ressaltando a importância da presença de espécies de Lactobacillus produtoras de bacteriocinas na composição dos probióticos (JIN et al. 1997; VICENT et al. 1959).

As bactérias intestinais, utilizando-se de ingredientes alimentares não absorvidos integralmente pelo hospedeiro - prebióticos - produzem alguns ácidos orgânicos, como o propiônico, o acético, o butírico, o láctico, bem como peróxido de hidrogênio, cujo espectro de ação inclui também a inibição do crescimento de bactérias patogênicas gram-negativas (SORRELS e SPECK, 1970; PRICE e LEE, 1970; CHERRINGTON et al. 1990).
Aparentemente a ação bacteriostática dos ácidos graxos é dependente do $\mathrm{pH}$, pois quanto maior a redução desse, maior a quantidade de ácido, com consequiente efeito antibacteriano mais intenso (SORRELS e SPECK, 1970). Não podemos descartar a idéia de que todas essas substâncias antibacterianas possam trabalhar em associação, não só entre si como fatores desencadeantes e processantes, mas também com o bloqueio físico.

Competição por nutrientes. Embora possa parecer incongruente que exista supressão do crescimento de alguma espécie bacteriana intestinal, devida à carência nutricional, exatamente pelo local em questão, têm sido demonstrado que esse fato é verdadeiro, chegando a reduzir drasticamente algumas espécies da microbiota intestinal (WILSON e PERINI, 1988).

Estímulo ao sistema imune. O status imunológico do hospedeiro está diretamente relacionado com a microbiota intestinal, uma vez que a carga antigênica resultante dessas bactérias induz ao estímulo do sistema imune (PERDIGON et al. 1993; TANNOCK, 1998). Alguns gêneros de bactérias intestinais, como o Lactobacillus e o Bifidobacterium estão diretamente relacionados com o estímulo da resposta imune por aumento da produção de anticorpos (LEE et al. 1993), ativação de macrófagos (SEKINE et al. 1994), proliferação de células T (YASUI e OHWAKI, 1991) e produção de intérferon (FULLER e GIBSON, 1997), entre outros. Entretanto, o verdadeiro mecanismo, pelo qual essas bactérias estimulam o sistema imune, ainda permanece com muitos pontos obscuros (TANNOCK, 1998).

\section{Probióticos na avicultura}

Atualmente existem diversos probióticos sendo comercializados no Brasil, contemplando diversas espécies animais. Há expectativa de que esse mercado se amplie, à medida que cada vez mais empresas e técnicos percebam a viabilidade desse tipo de produto, especialmente na avicultura.

Há dois aspectos extremamente positivos no uso dos probióticos na avicultura, ou seja, aquele que determina melhores índices zooeconômicos, como aumento no ganho de peso e melhor conversão alimentar em frangos de corte e incremento da produção de ovos em poedeiras (TORTUERO, 1973; JIN et al. 1996, 1997; ABDULRAHIM et al. 1996; NAHASHON et al. 1996) e a redução da colonização intestinal por alguns patógenos, incluindo-se Salmonella spp. (ANDREATTI FILHO et al. 1997, 1998; CORRIER et al. 1995; NURMI e RANTALA, 1973; SCHNEITZ, 1992; STAVRICK, 1992; ZIPRIN et al. 1993). 
ANDREATTI FILHO, R. L.; SAMPAIO, H. M. Probióticos e prebióticos: realidade na avicultura industrial moderna. / Probiotics and preobiotics: the reality in the modern poultry industry / Rev. educ. contin. CRMV-SP / Continuous Education Journal CRMV-SP, São Paulo, volume 2, fascículo 3, p. 059 - 071 , 1999.

Em alguns países há restrição no uso comercial de probióticos, em razão da exigência dos órgãos responsáveis em que a composição desses produtos seja totalmente conhecida e discriminada. Esse fato esbarra na constatação científica atual de que culturas definidas são menos efetivas que culturas indefinidas (STAVRIC e D'AOUST, 1993; CORRIER et al. 1995). Entretanto, inúmeros grupos de pesquisadores trabalham visando a obtenção de produto contendo bactérias totalmente conhecidas e em quantidades pré-determinadas, com o intuito de eliminar a possibilidade da transmissão de patógenos. Como ainda não foi estabelecido um critério definitivo e eficaz para isolar, selecionar, cultivar e manter as bactérias em condições de preservar a capacidade de proteção, um produto com quantidade e discriminação pré-definidos, preservando seu poder de ação, não foi ainda concluído. Existem inúmeras tentativas para obtenção desse tipo de produto. Na Tabela 1, podemos verificar a composição de diversas misturas definidas, que redundaram em proteção a aves desafiadas com Salmonella spp. As diversas combinações variam de, no mínimo, 28 até o máximo de 65 espécies bacterianas. Observando a diferença no número total de amostras e entre as espécies selecionadas, não podemos desconsiderar fator extremamente importante, que é a manutenção do equilíbrio entre as diversas espécies, pois em condições naturais, há determinadas espécies bacterianas, e em quantidades ideais, contribuindo para a manutenção do hospedeiro em condições saudáveis. A composição arti- ficial de algumas espécies de bactérias intestinais, muitas vezes, não atinge bons resultados provavelmente pelo rompimento desse equilíbrio microbiano. A preocupação com algumas espécies bacterianas na composição dos probióticos fica evidente na Tabela 1. Enterococcus, Bacteroides, Eubacterium e especialmente Lactobacillus e Bifidobacterium estão presentes em todas as misturas, ressaltando-se a importância dessas espécies para a efetiva ação dos probióticos.

Aparentemente, um número maior de espécies bacterianas determina um probiótico mais efetivo, quando comparado com produtos que apresentam número reduzido de espécies. Na verdade, culturas contendo em torno de 50 espécies bacterianas teriam maiores chances de manter o equilíbrio da microbiota cecal, quando comparado com culturas contendo número reduzido de bactérias. Só a partir de quatro espécies de bactérias é que se evidencia alguma proteção e, em misturas contendo mais de 20 espécies a proteção tende a ser mais efetiva (STAVRIC et al. 1985; STAVRIC, 1992).

Utilizando o conteúdo total de cecos provenientes de aves adultas, CORRIER et al. (1991), em um clássico trabalho sobre a ação das culturas cecais, demonstraram claramente que misturas indefinidas de bactérias cecais promovem a redução da colonização ou invasão de órgãos por $S$. enteritidis em aves (Tabela 2). Coerentemente, a redução da colonização por $S$. enteritidis pela ação da microbiota cecal é mais acentuada quando o desafio ocorre em menor concentração. Transpondo esta

Tabela 1 - Comparação da composição bacteriana de misturas definidas que protegeram aves contra Salmonella. Adaptado de STAVRIC (1992).

\begin{tabular}{|c|c|c|c|c|c|}
\hline \multirow[b]{2}{*}{ Gênero ou Tipo } & \multicolumn{5}{|c|}{ Misturas definidas } \\
\hline & 1982 & Im pey & $\begin{array}{l}\text { Stavric } \\
1985\end{array}$ & $\begin{array}{c}\text { Gleeson } \\
1989\end{array}$ & $\begin{array}{l}\text { corrier } \\
1995\end{array}$ \\
\hline Escherichia & 8 & 8 & 6 & $\quad \ldots$ & 2 \\
\hline Enterococcus & 2 & 2 & 8 & 7 & 7 \\
\hline Bacteroides & 4 & 5 & 11 & 6 & 1 \\
\hline Bacillus & 1 & 1 & -.- & $\cdots$ & $\cdots$ \\
\hline Fusobacterium & $\cdots$ & 1 & 2 & 2 & 1 \\
\hline Lactobacillus & 11 & 11 & 10 & 4 & 1 \\
\hline Eubacterium & 2 & 6 & 3 & 3 & 3 \\
\hline Propio nibacterium &.- & $\ldots$ & 1 & 1 & 4 \\
\hline Clostridium & 10 & 11 & 2 & $\cdots$ & $\cdots$ \\
\hline Bifido b acterium & 2 & 2 & 1 & 1 & 3 \\
\hline Lactococcus & $\cdots$ & $\cdots$ & $\cdots$ & $\cdots$ & 2 \\
\hline Citrobacter & $\cdots$ & $\cdots$ & $\cdots$ & $\cdots$ & 1 \\
\hline Enterobacter & $\cdots$ & $\cdots$ & $\cdots$ & -.. & 1 \\
\hline Pseudomonas & $\cdots$ & $\cdots$ & $\cdots$ & -.. & 1 \\
\hline Serratia & $\cdots$ & $\cdots$ & $\cdots$ & $\cdots$ & 1 \\
\hline Velllo nella & $\cdots$ & $\cdots$ & $\cdots$ & $\cdots$ & 1 \\
\hline Bastonetes gram + & 1 & 1 & 6 & 4 & $\cdots$ \\
\hline cocos gram + & 4 & 10 & $\cdots$ & $\cdots$ & $\cdots$ \\
\hline outros & 3 & 7 & $\ldots$ & 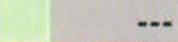 & ... \\
\hline$N^{\circ}$ total amostras & 48 & 65 & 50 & 28 & 29 \\
\hline
\end{tabular}




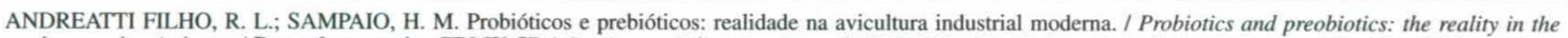
modern poultry industry / Rev. educ. contin. CRMV-SP / Continuous Education Journal CRMV-SP, São Paulo, volume 2, fascículo 3, p. 059 - 071, 1999.

Tabela 2 -Efeito de microbiota cecal anaeróbia e lactose sobre a colonização cecal de aves desafiadas com Salmonella enteritidis $(S E)^{A}$. Adaptado de CORRIER et al. (1991).

\begin{tabular}{|c|c|c|c|c|}
\hline \multirow{2}{*}{ Tratam en to } & \multirow{2}{*}{$\begin{array}{c}\text { In o c u lo } \\
\text { S.E }\end{array}$} & \multicolumn{2}{|c|}{ Pos itivo $S$. enteritid is I Total $(\%)^{B}$} & \\
\hline & & $100 \mathrm{dia}$ & $21^{\circ} \mathrm{dia}$ & \\
\hline Controle & $10^{6}$ & $15 / 15(100)$ & $15 / 15(100)$ & \\
\hline Microbiota & $10^{6}$ & $12 / 15(80)$ & $6 / 15(40) * *$ & \\
\hline Lactose & $10^{6}$ & $15 / 15(100)$ & $15 / 15(100)$ & \\
\hline Microbiota e Lactose & 106 & $11 / 15(73) *$ & $7115(47)^{* *}$ & \\
\hline Controle & $10^{4}$ & $14 / 15(93)$ & $14 / 15(93)$ & \\
\hline Microbiota & 104 & $13 / 14(93)$ & $4 / 15(27) * *$ & \\
\hline Lactose & $10^{4}$ & $12 / 14(86)$ & $13 / 15(87)$ & 8 \\
\hline Microbiota e Lactose & $10^{4}$ & $0 / 15(0)^{* *}$ & $1 / 15(7)^{* *}$ & \\
\hline
\end{tabular}

informação às condições de campo, podemos esperar resultados ainda mais promissores, pois em condições laboratoriais os desafios costumam ser bem maiores que os observados no campo, excetuando-se as condições de estresse. Nesse mesmo trabalho verifica-se que a adição de lactose à ração, funcionando como um prebiótico, incrementa a redução da colonização por $S$. enteritidis, o que não ocorre quando o carboidrato é administrado isoladamente.

Uma das formas mais freqüentes de disseminação das infecções paratifóides determinadas por Salmonella spp. é pelas fezes. Em virtude desse aspecto, é fundamental minimizar a disseminação desta bactéria através da excreção via fezes. ANDREATTI FILHO et al. (1997, 1998) demonstraram que o uso de microbiota cecal anaeróbia reduziu a quantidade de $S$. enteritidis nas fezes de aves. Nesses mesmos trabalhos, a ação isolada de lactose ou ácido acético não apresentou efeito similar na redução bacteriana quando comparado com a microbiota cecal anaeróbia (Figura 3). Já está claramente definido que os cecos, seguidos do reto e inglúvio, são os segmentos do trato digestivo com maior colonização por enterobactérias, especialmente Salmonella spp. Quando utilizamos esses três segmentos, além do duodeno, para verificar a colonização de $S$. enteritidis em aves tratadas com microbiota cecal anaeróbia, lactose ou ácido acético, constatamos que também nesses locais, seqüencialmente há redu- ção na colonização pela bactéria nas aves que receberam microbiota cecal anaeróbia, o que não ocorreu nas aves tratadas com lactose ou ácido acético. A ação da microbiota cecal sobre a colonização do trato digestivo e os cecos, funcionando como o maior reservatório de $S$. enteritidis, estão claramente demonstrados na Figura 4 (ANDREATTI FILHO et al. 1997, 1998).

\section{Fazendo e usando um probiótico}

Algumas características são imprescindíveis na composição de um probiótico, especialmente se esse produto deixa de ser apenas fruto de experiências laboratoriais e passe a ser comercializado. FULLER (1989) e GIBSON e ROBERFROID (1995) apresentam-nos as propriedades mais desejáveis de um probiótico, ou seja, apresenta condições de ser produzido em larga escala e de maneira viável, poder ser estocado e manter a sua viabilidade até o momento de uso, ter condições de per-

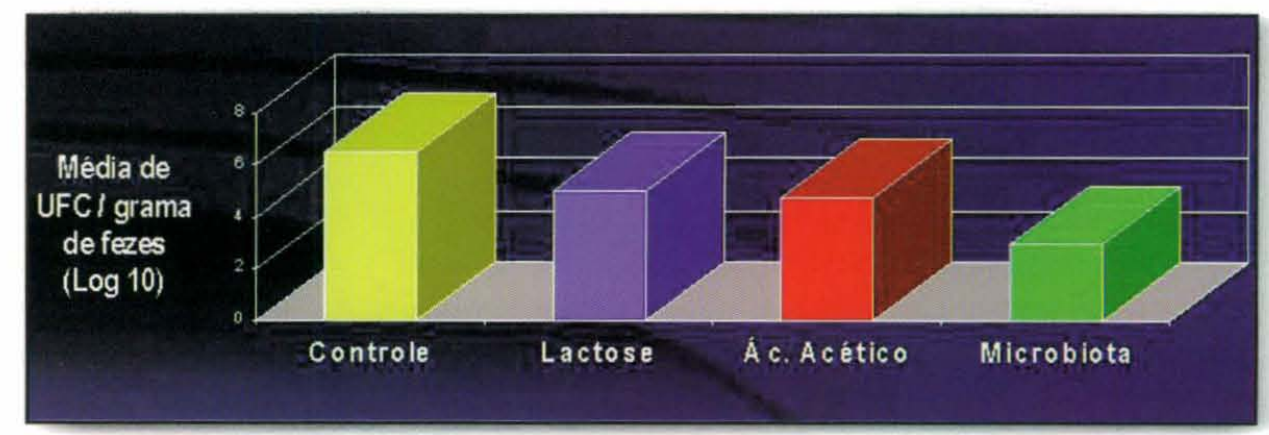

Figura 3 - Presença de Salmonella enteritidis nas fezes de aves desafiadas via intra-esofagiana, após tratamentos com lactose, ácido acético e microbiota cecal anaeróbia 
ANDREATTI FILHO, R. L.; SAMPAIO, H. M. Probióticos e prebióticos: realidade na avicultura industrial moderna. / Probiotics and preobiotics: the reality in the modern poultry industry / Rev. educ. contin. CRMV-SP / Continuous Education Journal CRMV-SP, São Paulo, volume 2, fascículo 3, p. 059 - 071, 1999.

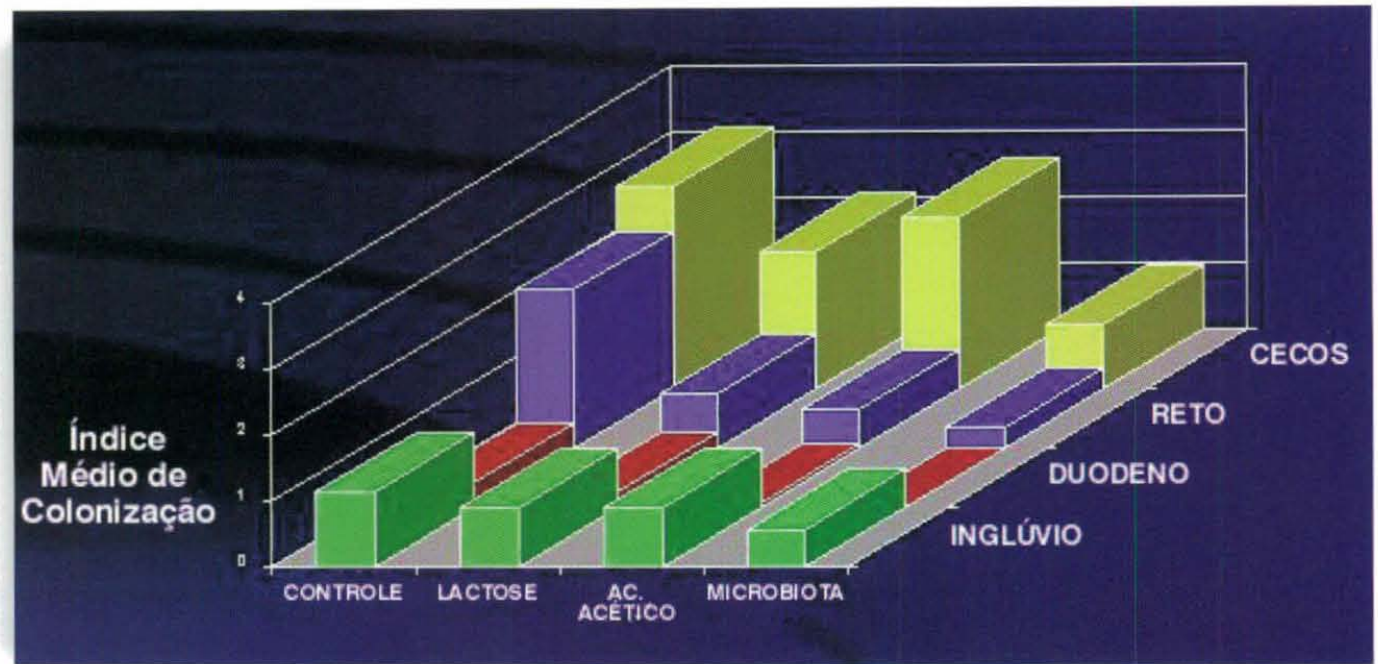

Figura 4 - Colonização de Salmonella enteritidis no trato digestivo de aves desafiadas via intra-esofagiana, após tratamentos com lactoses, ácido acético e microbiota cecal anaeróbia

manecer no ecossistema intestinal e que o hospedeiro animal seja beneficiado pelo seu uso. Essas são as condições desejáveis a um probiótico; entretanto, outros cuidados, muitas vezes determinantes para o sucesso de um produto, também devem ser observados, como a origem das bactérias que comporão o probiótico. Há necessidade que as bactérias sejam hospedeiro-específicas, a fim de que a máxima eficácia do produto seja atingida. $\mathrm{O}$ fluido do rúmen de bovinos ou fezes de eqüinos são ineficazes na prevenção à infecção por Salmonella spp. em galinhas. Mesmo entre aves de espécies diferentes há apenas proteção parcial, ou seja, uma microbiota obtida de perus determina proteção parcial em galinhas (frangos de corte ou poedeiras) e o inverso também é verdadeiro (STAVRIC, 1992; NURMI e RANTALA, 1973).

As aves doadoras deverão ser obrigatoriamente adultas, assegurando a presença de uma população bacteriana intestinal ampla e bem formada, além da garantia de que essas aves não contenham nenhum patógeno que possa contaminar a cultura que dará origem ao probiótico. O uso de aves SPF ("specific pathogenic free") como doadoras de microbiota talvez seja a maneira mais simples para obtenção de produto sem patógenos específicos.

A condição de anaerobiose é fundamental, no cultivo bacteriano, para manutenção da capacidade de exclusão pelas bactérias cecais. Entretanto, a condição de anaerobiose estrita parece ceder espaço atualmente ao uso de misturas de bactérias anaeróbias estritas e facultativas.

Por causa dos problemas com a padronização da microbiota intestinal, diversos estudos têm sido realizados com o intuito de obter-se produto que apresente boa uniformidade e efetividade na sua ação, por meio de melhor conservação dos microrganismos, com o conseqüente uso comercial pela indústria avícola (PIVNICK et al. 1982;
STAVRIC et al. 1985; ZIPRIN et al. 1993). As opções de manutenção da microbiota intestinal são os cultivos seriados através de passagem in vivo, liofilização e congelamento (GLEESON et al. 1989; PIVNICK et al. 1982; ZIPRIN et al. 1993). Cultivos puros congelados ou liofilizados tendem a perder a sua eficácia inicial, após algum tempo em relação ao material cecal fresco, que confere maior proteção (GLEESON et al. 1989; ZIPRIN et al. 1993). Entretanto, PIVNICK et al. (1982) demonstraram que embora o cultivo fresco proteja aves infectadas com S. typhimurium com mais consistência que culturas liofilizadas ou congeladas, essas em algumas partidas foram tão protetoras quanto a cultura fresca.

São descritos vários métodos de tratamento utilizando-se probióticos, como a adição à água de bebida, pulverização sobre as aves, inoculação via cloaca ou em ovos embrionados (in ovo), através de cama usada, em cápsulas gelatinosas e via intra-esofagiana (ANDREATTI FILHO et al. 1997; SCHNEITZ, 1992; ZIPRIN et al. 1993). A via de administração dos probióticos determina uma melhor ou pior capacidade de colonização intestinal pelas bactérias presentes no produto utilizado. A inoculação direta no esôfago/ inglúvio (intra-esofagiana) é a mais eficiente (STAVRIC, 1992). Entretanto, em virtude da necessidade de aplicação em massa, métodos de administração pela água de bebida ou pulverização são os mais indicados em condições de campo (SCHNEITZ, 1992). Devemos ter em mente que, pela própria característica da avicultura, onde há necessidade de tratar, medicar ou vacinar um elevado número de aves, em curto espaço de tempo e, sem minimizar a qualidade e a viabilidade intrínseca do produto que se está administrando, toda e qualquer via de aplicação em massa é sempre desejável, especialmente se estiver associada à manutenção da efetividade do produto envolvido. A aplicação de probióti$\cos$ in ovo tende a ser aperfeiçoada, sofisticando cada vez mais a já tecnificada avicultura. Todavia, a simplicidade e a praticidade, como a própria idéia de ação dos probióticos, sempre serão amplamente aceitas, especialmente quando da veiculação desse tipo de produto pela ração, seguindo-se a idéia dos prebióticos. Alheia a qualquer uma das vias de administração propostas, há a indicação de que os probióti- 
cos devam ser utilizados o mais precocemente possível nas aves, a fim de que as bactérias presentes no produto colonizem e multipliquem no trato intestinal, iniciando suas atividades benéficas ao hospedeiro antes desse ser contaminado por algum patógeno.

Com o crescente número de probióticos que atualmente vêm sendo produzidos e introduzidos no mercado, fazem-se necessários o controle de qualidade e a verificação da eficácia desses produtos. A constatação a campo da obtenção de melhores índices zooeconômicos é facilmente verificada, desde que sejam adotados parâmetros técnico-científicos adequados para aferição desses resultados. Além do que, com os índices de produtividade atualmente obtidos, que vem sendo tão marcantes , quaisquer avanços e benefícios em termos de produção, por menor que sejam, trarão retorno extremamente favorável à produção, com conseqüente benefício, tanto à indústria avícola quanto ao consumidor final. Os probióticos parecem enquadrar-se perfeitamente nesse contexto. Em relação a EC, reduzindo-se a quantidade de aves colonizadas por patógenos, como Salmonella spp., fazem-se necessários alguns testes laboratoriais que determinem os chamados fatores de proteção e colonização (PIVNICK et al. 1985), entre outros, que permitam verificar a eficiência do probiótico utilizado.

\section{Prebióticos: o que são?}

Recentemente, o termo prebiótico começou a ser utilizado para determinados ingredientes alimentares, que são utilizados especificamente por algumas bactérias da microbiota intestinal, melhorando a sua performance e, conseqüentemente, a do hospedeiro. Definem-se prebióticos como ingredientes alimentares não digeríveis que beneficiam a saúde do hospedeiro por estimular seletivamente o crescimento e/ou a atividade de um número limitado de bactérias no intestino (GIBSON e ROBERFROID, 1995; FULLER e GIBSON, 1997). A principal ação dos prebióticos é estimular o crescimento e/ou ativar o metabolismo de algum grupo de bactérias do trato intestinal (GIBSON e ROBERFROID, 1995).

Assim como para os probióticos, GIBSON e ROBERFROID (1995) descrevem as características imprescindíveis para que determinado produto ou substância possa ser denominada prebiótico, ou seja, não deve ser hidrolisado ou absorvido durante a sua passagem pelo trato digestivo superior, deve servir como substrato a uma ou mais bactérias intestinais benéficas que, por sua vez, serão estimuladas a crescer e/ou tornarem-se metabolicamente ativas, possuir a capacidade de alterar a microbiota intestinal de maneira favorável à saúde do hospedeiro e induzir efeitos benéficos sistêmicos ou na luz intestinal do hospedeiro. Desta maneira, podemos perceber claramente a simbiose entre os probióticos e os prebióticos, pois esses na dieta atuam como beneficiadores das bactérias intestinais presentes nos probióticos. Esta associação de funções traz ao hospedeiro benefícios também duplicados, pois, se temos a suplementação constante de prebióticos na dieta, sempre ocorrerá o favorecimento ao desenvolvimento das bactérias intestinais, com o conseqüente benefício ao hospedeiro.

Alguns carboidratos, peptídeos, proteínas e lipídeos podem ser inseridos no conceito de prebióticos; entretanto, entre os carboidratos, os denominados oligossacarídeos, que são cadeias curtas de polissacarídeos compostos de três a dez açúcares simples ligados entre si, são os que mais se enquadram na definição e nas características concernentes aos prebióticos. Alguns desses polissacarídeos, como os frutoligossacarídeos (FOS), podem substituir determinados antibióticos utilizados preventivamente, estimulando a produtividade em frangos de corte (AMMERMAN et al. 1989), por causa da influência sobre bactérias intestinais, como algumas espécies de Lactobacillus e Bifidobacterium, que têm seu crescimento estimulado pelo prebiótico, visto que esse pode ser utilizado como fonte de energia pelas bactérias intestinais. Arabinose, galactose, manose e, principalmente, lactose são outros carboidratos utilizados com o intuito de reduzir a colonização por Salmonella spp. (OYOFO et al. 1989; ZIPRIN et al. 1990). Embora os tratamentos isolados com carboidratos apresentem alguma ação na inibição da colonização por Salmonella spp., melhores resultados são obtidos quando as aves são inoculadas com culturas anaeróbias de microbiota cecal, juntamente com os carboidratos (ANDREATTI FILHO et al. 1998; ZIPRIN et al. 1990).

Quando FOS foram administrados isoladamente para aves, pouca influência sobre a colonização por Salmonella spp. foi observada, mas quando FOS foram utilizados em combinação com um probiótico, houve redução significativa na quantidade cecal de Salmonella spp. (BAILEY et al. 1991). Na Tabela 3, podemos constatar claramente a eficácia da associação da microbiota cecal com FOS em reduzir a quantidade de $S$. enteritidis nos cecos de aves desafiadas com 21 dias de idade. Em todos os períodos após o desafio - 01, 07 e 14 dias - a associação do probiótico com o prebiótico demonstrou, pela redução na colonização por $S$. enteritidis, ser significativamente distinta dos grupos não tratados (FUKATA et al. 1999). Já está demonstrado que FOS são seletivamente fermentados por diversas espécies de Bifidobacterium e, como conseqüência pode haver redução na 
ANDREATTI FILHO, R. L.; SAMPAIO, H. M. Probióticos e prebióticos: realidade na avicultura industrial moderna. / Probiotics and preobiotics: the reality in the modern poultry industry / Rev. educ. contin. CRMV-SP / Continuous Education Journal CRMV-SP, São Paulo, volume 2, fascículo 3, p. 059 - 071, 1999.

Tabela 3 -Efeito de microbiota cecal e oligossacarídeos (FOS) A 0,1\% na ração, sobre a quantidade de Salmonella enteritidis (SE) presente no conteúdo cecal de aves desafiadas com 21 dias de idade. Adaptado de FUKATA et al. (1999).

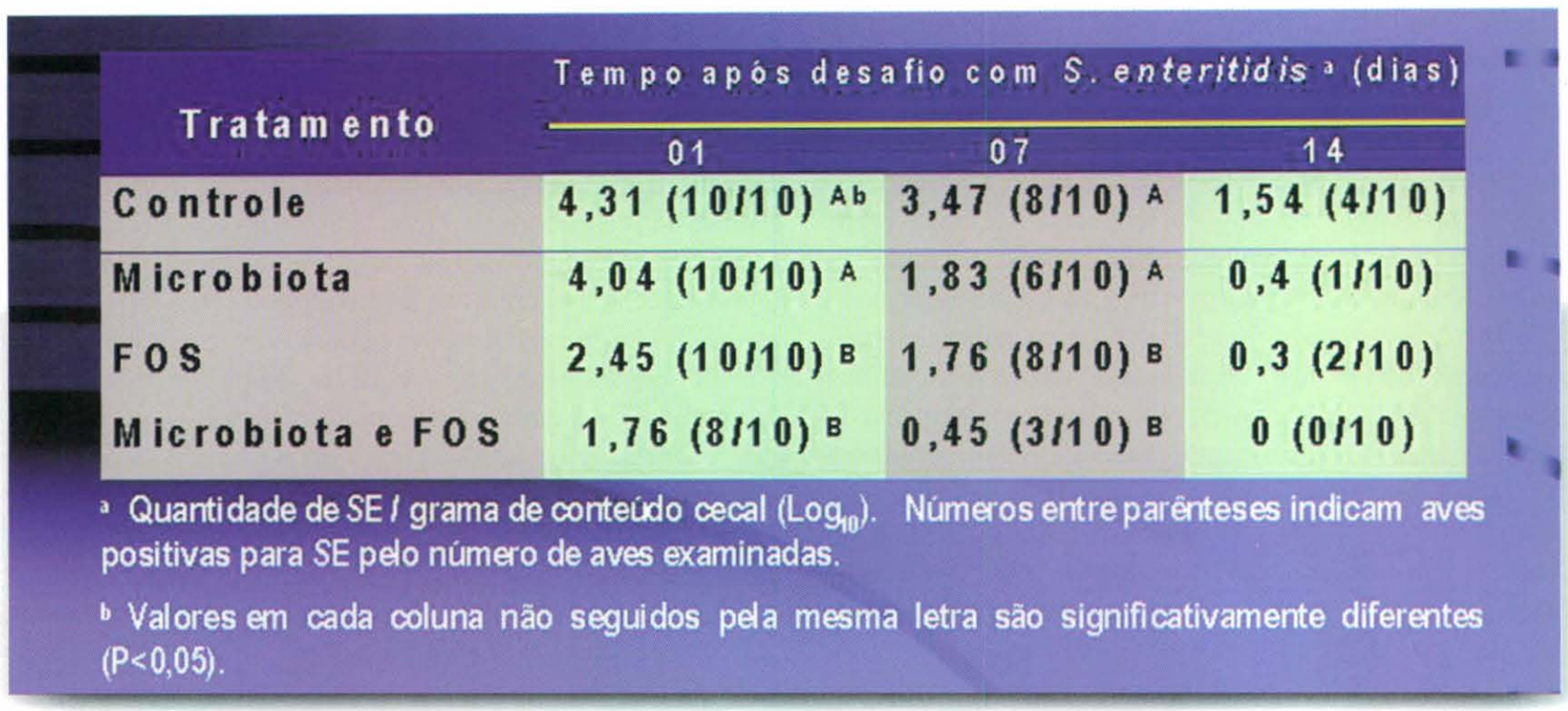

quantidade de outras bactérias, como Bacteroides, Clostridium e coliformes (GIBSON e ROBERFROID, 1995).

Fontes de oligossacarídeos. Sementes e raízes de alguns vegetais são as fontes naturais mais comuns de oligossacarídeos. Chicória, cebola, alho, alcachofra, aspargo, cevada, centeio, bem como soja, grão-de-bico e tremoço são exemplos de alguns vegetais com maior ou menor concentração de oligossacarídeos (PETTERSON e MACKINTOSH, 1994) que, por sua vez, podem ser extraídos pelo cozimento ou através de ação enzimática ou álcool (SLOMINSKI et al. 1994). Há também os oligossacarídeos sintéticos obtidos da polimerização direta de alguns dissacarídeos, através do fracionamento da parede celular de leveduras ou fermentação de polissacarídeos (MANLEY e RICHARDS, 1994).

\section{Por que usar prebióticos?}

O uso dos oligossacarídeos pode reduzir o crescimento de diversas bactérias intestinais, patogênicas ou não, pela redução do $\mathrm{pH}$, em virtude do aumento da quantidade de ácido láctico presente nos cecos (CHOI et al. 1994). Algumas bactérias podem reconhecer sítios de ligação nos oligossacarídeos como sendo da mucosa intestinal, reduzindo-se a colonização intestinal por bactérias patogênicas. Isso feito, além da menor incidência de infecções, teremos a mucosa intestinal inteiramente apta às suas funções de secreção, digestão e absorção de nutrientes (IJI e TIVEY, 1998). Especificamente com S. typhimurium, OYARZABAL e CONNER (1995), demonstraram que o crescimento desta bactéria é inibido em presença de FOS puro. Em experimento in vivo, CHOI et al. (1994) observaram redução na colonização intestinal por $S$. typhimurium em aves alimentadas com ração contendo FOS, quando comparado com aves sem a referida suplementação. Especula-se que os oligossacarídeos possam atuar também estimulando o sistema imune, por meio da redução indireta da translocação intestinal por patógenos, que determinariam infecções após atingir a corrente sangüínea (MONSAN e PAUL, 1995; IJI e TIVEY, 1998). MONSAN e PAUL, 1995, demonstraram que o equilíbrio proporcionado pelos oligossacarídeos à microbiota intestinal pode-se traduzir em maior ganho de peso em animais. Entretanto, paralelamente ao aumento no ganho de peso corporal em frangos de corte e perus, o uso de alguns oligossacarídeos pode proporcionar aumento no consumo de ração, redundando em uma conversão alimentar não significativamente eficiente (IJI e TIVEY, 1998; SAVAGE et al. 1997).

\section{Conclusões}

Está claramente demonstrado que os probióticos e os prebióticos induzem a microbiota intestinal ao equilíbrio, conseqüentemente determinando efeitos benéficos ao hospedeiro, seja no homem ou nos animais. Esses efeitos vão desde a supressão de agentes patogênicos até a obtenção de melhores condições de absorção de nutrientes. Na avicultura, esses efeitos são particu- 
larmente interessantes, visto que, com o equilíbrio e a reposição da microbiota intestinal por esses produtos, as aves conseguem enfrentar em melhores condições a todo o estresse desencadeado pelos modernos sistemas de produção.

A utilização de produtos naturais, como os probióticos e os prebióticos, vem ao encontro tanto da indústria avícola, ansiosa por substitutos dos tradicionais promotores de crescimento, como ao dos consumidores, exigindo sempre produtos de melhor qualidade.

Recentemente, produtos como probióticos e prebióticos começaram a ganhar destaque como os denominados alimentos funcionais, mediante a possibilidade de reduzir doenças e proporcionar mais saúde ao hospedeiro. Os alimentos funcionais podem ser definidos como produtos alimentícios que além de conter os nutrientes básicos essenciais, possuem a condição específica de beneficiar ao hospedeiro, através de melhorias na sua saúde. Com o advento do conceito de que a dieta controla e regula inúmeras funções no organismo, contribuindo para a boa saúde do hospedeiro, originou-se o termo alimento funcional e a possibilidade de novos desenvolvimentos dentro desta área.

Em medicina veterinária, mais precisamente na avicultura e na suinocultura, devemos começar a nos familiarizar com termos como probióticos, prebióticos, alimentos funcionais e ainda, simbióticos. Termos que aos poucos vêm ganhando espaço, sendo reconhecidos pela sua utilidade e importância. Os simbióticos, dentro da classe de alimentos funcionais, vêm a ser a mistura de probióticos e prebióticos em um só produto, trazendo, além de componentes da microbiota intestinal, também substâncias que estimulem o desenvolvimento e a atividade desta mesma microbiota. Esses produtos tendem a ser, indubitavelmente, importante segmento das indústrias veterinária e farmacêutica, privilegiando, além do bem-estar do hospedeiro, também o seu desenvolvimento, especialmente na produção de proteína animal.

\section{SUMMARY}

This article is a reviews on the use of probiotics and prebiotics in commercial poultry industry. The importance of functional feeds is emphasized in relation to their composition and activity on the intestinal of these animals. Their mode of action and the benefits to poultry breeding are also presented. These functional feeds may probably substitute growth promoters in the future, for they reduce production costs and are responsible for better quality poultri products.

Key words: probiotics, prebiotics, symbiotics, functional feeds, competitive exclusion, poultry industry.

\section{REFERÊNCIAS BIBLIOGRÁFICAS}

1 - ABDULRAHIM S.M.; HADDADIN, M.S.Y.; HASHLAMOUN, E.A.R.; ROBINSON, R.K. The influenceof Lactobacillus acidophilus and bacitracin on layer performance of chickens and cholesserol content of plasma and egg yolk. British Poultry Science., v.37, p.341-6, 1996.

2 - AMMERMAN, E.; QUARLES, C.; TWINING JUNIOR, P.V. Evaluation of fructooligosaccharides on performance and carcass yield of male broilers. Poultry Science., v.68, p.167, 1989.

3 - ANDREATTI FILHO, R.L.; SILVA, E.N.; CURI, P.R. Ácidos orgânicos e microbiota cecal anaeróbia no controle da infecção experimental de frangos por Salmonella typhimurium e Salmonella enteritidis. Arquivo Brasileiro de Medicina Veterinária e Zootecnia., v.49, p.661-72, 1997.

4 - ANDREATTI FILHO, R.L.; SILVA, E.N.; CURI, P.R. Control of experimental infection of broilers by Salmonella Enteritidis and $S$. Typhimurium with the use of organic composites and anaerobic cecal mcroflora. In: INTERNATIONAL SYMPOSIUM ON FOOD-BORNE SALMONELLA IN
POULTRY, Baltimore, 1998. Proceedings. American Association of Avian Pathology, 1998. p.53.

5 - BAILEY, J. S.; BLANKENSHIP, L.C.; COX, N.A. Effect of fructooligosaccharide on Salmonella colonization of the chicken intestine. Poultry Science, v.70, p.2433-8, 1991.

6 - BAILEY, J. S. Control of Salmonella and Campylobacter in poultry production. A summary of work at Russel Research Center. Poultry Science, v.72, p.1169-73, 1993.

7 - CHERRINGTON, C.A.; HINTON, M.; CHOPRA, I. Effect of short-chain organic acids on macromolecular synthesis in Escherichia coli. Jounal of Bacteriology, v.68, p.69-74, 1990.

8 - CHOI, K.H.; NAMKUNG, H.; PAIK, I.K. Effects of dietary fructooligosaccharides on the suppression of intestinal colonization of Salmonella typhimurium in broiler chickens. Korean Journal of Animal Science, v.36, p. 27184, 1994. 
9 - CONWAY, P.L.; GORBACH, S.L.; GOLDIN, B.R. Survival of lactic acid bacteria in the human stomach and adhesion to intestinal cells. Journal Dairy Science, v.70, p.1-12, 1987.

10 - CORRIER, D.E.; HARGIS, B.M.; HINTON JUNIOR, A.; LINDSEY, D.; CALDWELL, D.; MANNING, J.; DeLOACH, J. R. Effect of anaerobic cecal microflora and dietary lactose on colonization resistance of layer chicks to invasive Salmonella enteritidis. Avian Diseases, v.35, p.337-43, 1991.

11 - CORRIER, D.E.; NISBET, D. J. SCANLAN, C.M.; HOLLISTER, A.G.; CALDWELL, D. J.; THOMAS, L.A.; HARGIS, M.; TOMKINS, T.; DeLOACH J.R. Treatment of commercial broiler chickens with a characterized culture of cecal bacteria to reduce Salmonellae colonization. Poultry Science, v.74, p.1093-101, 1995.

12 - DAY, C.A. Competitive exclusion in poultry: a review. Worcessershire: Life-Care Products. 1992. 18p.

13 - FUKATA, T.; SASAI, K.; MIYAMOTO, T.; BABA, E. Inhibitory effects of competitive exclusion and fructooligosaccharide, singly and in combination, on Salmonella colonization of chicks. Journal Food Protection, v.62, p.229-33, 1999.

14 - FULLER, R. Probiotics in man and animals. Journal Applied Bacteriology, v.66, p.365-78, 1989.

15 - FULLER, R.; GIBSON, G.R. Modification of the intestinal microflora using probiotics and prebiotics. Scandinavian Journal Gastroenterology, v.32, p.28-31, 1997.

16 - GIBSON, G.R.; ROBERFROID, M.B. Dietary modulation of the human colonic microbiota: introducing the concept of prebiotics. Journal Nutrition, v.125, p.1401-12, 1995.

17 - GLEESON, T.M.; STAVRIC, S.; BLANCHFIELD, B. Protection of chicks against Salmonella infection with a mixture of pure cultures of intestinal bacteria. Avian Diseases, v.33, p.636-42, 1989.

18 - GUSILS, C.; CHAIA, A.P.; GONZÁLEZ, S.; OLIVER, G. Lactobacilli isolated from chicken intestines: potential use as probiotics. Journal Food Protection, v.62, p.252-6, 1999.

19 - HAVENAAR, R.; BRINK, B.T.; HUIS VELD, J. H. H.; FULLER, R. Selection of strains for probiotics use. In: FULLER, R. Probiotics: the scientific basis. London: Chapman and Hall, 1992. p.209-24.

20 - IJI, P.A.; TIVEY, D.R. Natural and synthetic oligosaccharides in broiler chicken diets. World Poultry Science Journal, v.54, p.129-43, 1998.

21 - IMPEY, C.S.; MEAD, G.C.; GEORGE, S.M. Competitive exclusion of Salmonella from the chick caecum using a defined mixture of bacterial isolates from the caecal microflora of an adult bird. Journal Hygiene, v.89, p.479-90, 1982.

22 - IMPEY, C.S.; MEAD, G.C.; GEORGE, S.M. Evaluation of treatment with defined and undefined mixture of gut microorganisms for preventing Salmonella colonization in chicks and turkey poults. Food Microbiology, v.1, p.143-7, 1984.

23 - JIN, L.Z.; HO, Y.W.; ABDULLAH, N.; JALALUDIN, S. Influence of dried Bacillus subtilis and Lactobacilli cultures on intestinal microflora and performance in broilers. AsianAustralasian Journal Animal Science, v.9, p.397-404, 1996.
24 - JIN, L.Z.; HO, Y.W.; ABDULLAH, N.; JALALUDIN, S. Probiotics in poultry: modes of action. World Poult. Science Journal, v.53, p.351-68, 1997.

25 - KLAENHAMMER, T.R.; AHN, C.; MURIANA, P.M. Lacta$\operatorname{cin} \mathrm{F}$, a small hydrophobic heat-stable bacteriocin from $\mathrm{Lac}$ tobacillus johnsonii. In: VUYST, L.D.; VANDAMME, E.J. Bacteriocins of lactic acid bacteria: microbiology, genetics, and applications. London: Chapman and Hall, 1994. p.377-97.

26 - KORSHUNOV, U.M.; SINITSYNA, N.A.; GINODMAN, G.A.; PINEGIN, B.V. Correction of intestinal microflora in chemotherapeutic dysbacteriosis using bifidobacterial and lactobacterial autologous strains. Z. Mikrobiologie Epidemiologie Immunobiologie, v.9, p.20-5, 1985.

27 - LEE, J.; AMETANI, A.; ENOMOTO, A.; SATO, Y.; MOTOSHIMA, H.; IKE, F.; KAMINOGAWA, S. Screening for the immunopotentiating activity of food microorganis$\mathrm{ms}$ and enhancement of the immune response by Bifidobacterium adolescentis M101-4. Bioscience. Biotechnology. Biochemistry., v.57, p.2127-32, 1993.

28 - LILLY, D.M.; STILLWELL, R.H. Probiotics: growth promoting factors produced by microorganisms. Science, v.147, p.747-8, 1965.

29 - MANLEY, H.M.; RICHARDS, G.N. Nutritional gains from sucrose caramels, a synopsis of the potential. International Sugar Journal, v.96, p.1144, 1994.

30 - METCHNIKOFF, E. Prolongation of life. New York: Putnam, 1907.

31 - MILES, R.D. Manipulation of the microflora of the gastrointestinal tract: natural ways to prevent colonization by pathogens. In: ALTECH BIOTECHNOLOGY IN THE FEED INDUSTRY, Florida, 1993. Proceedings. p.133-50.

32 - MONSAN, P.F.; PAUL, F. Oligosaccharide feed additives. In: WALLACE, R.J.; CHESSON, A. Biotechnology in animal feeds and feeding. Weinheim: VCH Verlagsgesellschaft, 1995. p.233-45.

33 - NAHASHON, S.N.; NAKAUE, H.S.; MIROSH, L.W. Nutrient retention and production parameters of Single Comb White Leghorn layers fed diets with varying crude protein levels and supplemented with a direct-fed microbial. Animal Feed Science, Technologie., v.61, p.17-26, 1996.

34 - NISHIZAWA, Y. Physiological activity of bifidobacteria. Shonika Shinryo, v.23, p.1213-8, 1960.

35 - NURMI, E.; RANTALA, M. New aspects of Salmonella infection in broiler production. Nature, v.241, p.210-1, 1973.

36 - OYARZABAL, O.A.; CONNER, D.E. In vitro fructooligosaccharide utilization and inhibition of Salmonella spp. by selected bacteria. Poultry Science, v.74, p.1418-25, 1995.

37 - OYOFO, B.A.; DeLOACH, J.R.; CORRIER, D.E.; NORMAN, J. O.; ZIPRIN, R.L.; MOLLENHAUER, H.H. Effects of carbohydrates on Salmonella typhimurium colonization in broiler chickens. Avian Diseases, v.33, p.531-4, 1989.

38 - PERDiGON, G.; ALVAREZ, S.;MEDICI, M.; HOLGADO, A.A.P.R. Influence of the use of Lactobacillus casei as na oral adjuvant on the levels of secretory immunoglobolin A during na infection with Salmonella typhimurium. Food Agriculture Immunologie, v.5, p.27-37, 1993. 
39 - PETTERSON, D.S.; MACKINTOSH, J. B. The chemical composition and nutritive value of australian grain legumes. Grains Research and Development Corporation: Brisbane, Australia. 1994. p.10-3, 38-41.

40 - PIVNICK, H.; BLANCHFIELD, B.; RIGBY, C.; ORMSBY, E. Comparison of fresh feces with lyophilized and frozen cultures of feces as inocula to prevent Salmonella infection in chicks. Journal of Food Protection, v.45, p.118894, 1982.

41 - PIVNICK, H.; BARNUM, D.; STAVRIC, S.; GLEESON, T.; BLANCHFIELD, B. Investigations on the use of competitive exclusion to control Salmonella in poultry. In: INTERNATIONAL SYMPOSIUM ON SALMONELLA, Philadelphia, 1985. Proceedings. American Association of Avian Pathologists: Univ. Pennsylvania, 1985, p.80-7.

42 - PRICE, R. J.; LEE, J.S. Inhibition of Pseudomonas species by hydrogen peroxide producing lactobacilli. Journal Milk Food Technology, v.33, p.13-8, 1970.

43 - RASIC, J. L. The role of dairy foods containing bifido and acidophilus bacteria in nutrition and health. North European Dairy Journal, v.4, p.80-8, 1983.

44 - RETTGER, L.F.; CHAPLIN, H.A. Treatise on the transformation of the intestinal flora with special reference to the implantation of Bacillus acidophilus. New Haven: Yale University Press, 1921.

45 - SALANITRO, J.P.; BLAKE, I.G.; MUIRHEAD, P.A.; MAGLIO, M.; GOODMAN, J.R. Bacteria isolated from the duodenum, ileum and cecum of young chicks. Applied Environmental Microbiology, v.35, p.782-90, 1978.

46 - SAVAGE, T.F.; ZAKRZEWSKA, E.I.; ANDREASEN, J. R. The effects of feeding mannan oligosaccharide supplemented diets to poults on performance and the morphology of the small intestine. In: SOUTHERN CONFERENCE ON AVIAN DISEASES. Southern Poultry Science Society, 1997.

47 - SCHNEITZ, C. Automated droplet application of a competitive exclusion preparation. Poultry Science, v.71, p.2125-8, 1992.

48 - SEKINE, K.; TOIDA, T.; SAITO, M.; KUBOYAMA, M.; KAWASHIMA, T. A new morphologically characterized cell wall preparation (whole peptidoglycan) from Bifidobacterium infantis with a higher efficacy on the regression of an established tumor in mice. Cancer Research, v.45, p.13007,1985 .

49 - SEKINE, K.; WATANABE-SEKINE, E.; TOIDA, T.; KAWASHIMA, T.; KATOAKA, T.; HASHIMOTO, Y. Adjuvant activity of the cell wall of Bifidobacterium infantis for in vivo immune responses in mice. Immunopharmacology Immunotoxicology, v.16, p.589-609, 1994.

50 - SILVA, E.N.; SNOEYENBOS, G.H.; WEINACK, O.M.; SMYSER, C.F. The influence of native gut microflora on the colonization and infection of Salmonella gallinarum in chickens. Avian Diseases, v.25, p.68-73, 1981.
51 - SLOMINSKI, B.A.; CAMPBELL, L.D.; GUENTER, W. Oligosaccharides in canola meal and their effect on nonstarch polysaccharide digestibility and true metabolizable energy in poultry. Poultry Science, v.73, p.156-62, 1994.

52 - SORRELS, K.M.; SPECK, M.L. Inhibition of Salmonella gallinarum by culture filtrates of Leuconostoc citrovorum. Journal Dairy Science,, v.59, p.338-43, 1970.

53 - STAVRIC, S.; GLEESON, T.M.; BLANCHFIELD, B.; PIVNICK, H. Competitive exclusion of Salmonella from newly hatched chicks by mixtures of pure bacterial cultures isolated from fecal and cecal contents of adult birds. Journal Food Protecttion., v.48, p.778-82, 1985.

54 - STAVRIC, S. Microbial colonization control of chicken intestine using defined cultures. Food Technology, v.43, p.93-8, 1987.

55 - STAVRIC, S. Defined cultures and prospects. International Journal Food Microbiology, v.15, p.245-63, 1992.

56 - STAVRIC, S.; D'AOUST, J. Y. Undefined and defined bacterial preparations for the competitive exclusion of Salmonella in poultry - a review. Journal Food Protection, v.56, p.17380,1993

57 - TAGG, J.R.; DAJANI, A.S.; WANNAMAKER, L.W. Bacteriocins of gram-positive bacteria. Bacteriology Review, v.40, p. $722-56,1976$

58 - TANNOCK, G.W. Studies of the intestinal microflora: a prerequisite for the development of probiotics. International Dairy Journal, v.8, p.527-33, 1998.

59 - TORTUERO, F. Influence of implantation of Lactobacillus acidophilus in chicks on the growth, feed conversion, malabsorption of fats syndrome and intestinal flora. Poultry Science, v.52, p.197-203, 1973.

60 - UPRETI, G.C.; HINDSDILL, R.D. Production and mode of action of Lactocin 27: Bacteriocin from a homofermentative Lactobacillus. Antimicrobial Agents and Chemotherapy, v.7, p.139-45, 1975 .

61 - VICENT, J. G.; VEONETT, R.C.; RILEY, R.G. Antibacterial activity associated with Lactobacillus acidophilus. Journal of Bacteriology, v.78, p.477-84, 1959.

62 - WILSON, K.H.; PERINI, F. Role of competition for nutrients in suppression of Clostridium difficile by the colonic microflora. Infections and Immunology., v.56, p.2610-4, 1988.

63. YASUI, H; OHWAKI, M. Enhancement of immune response in Peyer patch cells cultured with Bifidobacterium breve. Journal Dairy Science,, v.74, p.1187-95, 1991.

64 - ZIPRIN, R.L.; CORRIER, D.E.; HINTON JUNIOR, A.; BEIER, R.C.; SPATES, G.E.; DeLOACH, J. R.; ELISSALDE, M.H. Intracloacal Salmonella typhimurium infection of broiler chickens: reduction of colonization with anaerobic organisms and dietary lactose. Avian Diseases, v.34, p.749-53, 1990.

65 - ZIPRIN, R.L.; CORRIER, D.E.; DeLOACH, J. R. Control of established Salmonella typhimurium intestinal colonization with in vivo-passaged anaerobes. Avian Diseases, v.37, p.183-8, 1993. 